\title{
Siete pliegos impresos en Cuenca por Juan de Cánova
}

\author{
Joan Mahiques Climent \\ Universitat de Barcelona \\ jmahiques@ub.edu \\ Helena Rovira i Cerdà \\ Universitat de Barcelona \\ hrovira@ub.edu
}

Recepción: 27/09/2013, Aceptación: 24/10/2013, Publicación: 20/12/2013

\begin{abstract}
Resumen
Estudiamos desde el punto de vista bibliográfico siete pliegos sueltos, uno en prosa más seis en verso, que forman parte de un volumen de la Biblioteca Comunale Augusta de Perugia catalogado bajo la signatura [I L 1402]. En algunos de los ejemplares figuran el lugar y la fecha de impresión, es decir, Cuenca y los ańos 1557 o 1558. A partir de estos datos y del análisis formal de las siete ediciones, podemos atribuirlas todas ellas a la tipografía de Juan de Cánova. Dos de los siete pliegos transmiten poemas no localizados en ninguna otra fuente impresa o manuscrita, hasta donde hemos podido alcanzar en nuestra investigación. Además, el hecho de que una de estas poesías sea en catalán y de autor valenciano (Onofre Almudéver) nos hace sospechar que dichos pliegos, por lo menos en parte, fueron impresos a instancias de algún librero de Valencia.
\end{abstract}

Palabras clave

Siglo xvI; Juan de Cánova; pliegos sueltos; poesía; transmisión textual

\begin{abstract}
Seven chapbooks printed in Cuenca by Juan de Cánova

In this paper, we study from a bibliographic point of view seven chapbooks, one in prose and the rest in verse, which are bound in one volume preserved in the Biblioteca Comunale Augusta, Perugia, catalogued under the shelfmark [I L 1402]. Some of these editions include the place (Cuenca) and the date of printing (1557 or 1558). From this information and from the formal analysis of the seven editions, it is possible to ascribe all of them to the press of Juan de Cánova. Two of the seven chapbooks transmit poems that we have not located in any other handwritten or printed source, as far as it has been achieved in our research. Furthermore, the fact that one of these poems is in Catalan and has a Valencian author (Onofre Almudéver) makes us suspect that those chapbooks,
\end{abstract}


at least in part, were printed at the request of a bookseller established in Valencia.

\section{Keywords:}

Spanish sixteenth century; Juan de Cánova; chapbook; poetry; textual transmission

En la Biblioteca Comunale Augusta de Perugia, bajo la signatura [I L 1402], se conserva un volumen facticio de pliegos sueltos, que a partir de ahora mencionaremos bajo la sigla $P$. En total, contiene 34 ediciones diferentes, cuyos testimonios ascienden en su globalidad al número de 44, pues en muchos casos se han conservado repetidos dos o tres ejemplares, íntegros o mutilados. Entre todos los pliegos, los que indican el lugar y la fecha, o solo uno de ambos aspectos, remiten a Cuenca o Valencia y al intervalo comprendido entre los años 1552 y 1563 . La localidad manchega se consigna explícitamente en cinco de las ediciones. ${ }^{1}$ Una de ellas, que en nuestras descripciones bibliográficas hemos clasificado bajo el núm. [1], presenta en la parte inferior de la orla de la portada un escudo con una cruz, en cuyos lados se leen letras diferentes: «I» a la izquierda, «C» a la derecha. Y justo debajo de la cruz, todavía se añade una "A» circunscrita a un triángulo. Dicho anagrama lo encontramos en la marca de impresor de algunos volúmenes que salieron (tanto en Cuenca como en Salamanca) de los talleres de Juan de Cánova. ${ }^{2}$ Por estas razones y por otras que iremos desgranando más adelante, vinculamos a este impresor los siete pliegos que estudiaremos en este artículo. Tres de ellos son de 1557, y uno de

1. La primera pista sobre $P$ la tenemos en una nota bibliográfica de Wilkinson (2010: 485, núm. 12385) sobre una de las 34 ediciones. Posteriormente, Infantes $(2012$; 2013) ha presentado globalmente este volumen en el primer trabajo, mientras que en el segundo describe con detalle su contenido individuando cada uno de los ejemplares que lo constituye. Por nuestra parte, debemos agradecer toda la información cedida por Paolo Renzi, que, desde la Biblioteca Comunale Augusta de Perugia, clasificó por primera vez íntegramente el contenido de cada uno de los pliegos de $P$, facilitándonos no solamente dicha información sino también los trámites para obtener la reproducción fotográfica que hemos utilizado para redactar este artículo. Advertimos, pues, que no hemos consultado in situ los originales. Aparte de los siete pliegos, hay todavía otro impreso atribuido igualmente a Juan de Cánova, que data de 1552 y que pro- bablemente fue impreso en Salamanca (Mahiques/Rovira 2013). Asimismo, Infantes (2013: 33-34, núm. $1^{\text {bis }}$ ) atribuye a este mismo impresor no solamente los siete pliegos que nosotros estudiaremos sino también un pliego acéfalo que consideramos salido del taller valenciano de Joan Navarro (Rovira i Cerdà 2015a).

2. Dicha marca es reproducida y descrita por Alfaro Torres (2002: 50-52): «La marca tipográfica (V. lám. 8) que utiliza desde 1554 en Salamanca, y en 1560 en Cuenca representa dentro de una cartela flanqueada a los lados por dos sátiros, cuya parte inferior contiene el anagrama del impresor, rematada por una cabeza de carnero, un óvalo que contiene la lucha de San Jorge, montado en un pegaso, con el dragón. Rodea este óvalo la leyenda: [christus] CONSILIO ET VIRTVTE CHIMERAN SVPERARI, ID EST, FORTIORES ET DECEPTORES». Véase también Vindel (1942: 181-182, núms. 236-238). 
1558. Otros tres, sin fecha, se asemejan sobremanera al de 1558, por lo que les hemos asignado la indicación [circa 1558], aunque esta cronología no debe tomarse en un sentido restrictivo, pues la datación de dichos impresos podría fluctuar en un intervalo de varios años. Para facilitar una fluida alusión a estas ediciones conquenses, ofreceremos a continuación una tabla donde se indica el lugar que cada una de ellas ocupa en $P$. A partir de ahora nos referiremos a cada caso concreto ańadiendo el número con que nosotros identificamos estos siete pliegos.

\begin{tabular}{|c|c|}
\hline $\begin{array}{c}\text { Fol. que } \\
\text { ocupan en el } \\
\text { volumen y } \\
\text { núm. que les } \\
\text { asignamos }\end{array}$ & Pliegos sueltos \\
\hline $1^{\mathrm{r}-\mathrm{v}}[4]$ & $\begin{array}{l}\text { Coplas de: si me vieras | Juan, a lo spiritual; nueuamen } \mid \text { te compuestas. } \\
\text { Ańo. | M.D.L.viij. | Jmpresso en Cuenca. [Ấpodo] }\end{array}$ \\
\hline $2^{\mathrm{r}-\mathrm{v}}[4]$ & $\begin{array}{l}\text { Coplas de: si me vieras | Juan, a lo spiritual; nueuamen | te compuestas. } \\
\text { Año. | M.D.L.viij. | Jmpresso en Cuenca. [Ấpodo] }\end{array}$ \\
\hline $9-12^{\mathrm{v}}[2]$ & $\begin{array}{l}\text { OBRA NVEVAMEN- } \mid \text { te hecha, en la qual se contiene vna } \mid \text { platica } \\
\text { de entre la Muerte y la Vida } \mid \text { sacada y traduzida de nueuo vergel | } \\
\text { de Olorosas flores, sembradas por la } \mid \text { dolorosa Muerte, y cogidas } \\
\text { por la | trabajosa Vida. } 1557 \text {. | Argumento de la Obra. | NVEVO } \\
\text { VERGEL DE } \mid \text { suaue arboleda de Olorosas flores sem } \mid \text { bradas por la } \\
\text { triste Muerte: y cogidas por la trabajosa vi } \mid \text { da. Para sustentacion de } \\
\text { los cuerpos humanos, y gloria | para el anima. Nueuamente trobado. } \\
\text { En el qual se trata } \mid \text { cierta platica entre la Muerte y la Vida, es de muy } \\
\text { pro= | uechosos y consolatorios exemplos para los mundanos. }\end{array}$ \\
\hline $15-18^{v}[6]$ & $\begin{array}{l}\text { Siguen se quatro obras compuestas | por Nofre Almodeuar. | La primera } \\
\text { es vn chiste sa | cado ala letra sobre el euan } \mid \text { gelio dela Samaritana. | } \\
\text { La segunda. El chiste de } \mid \text { la Chananea. | I La tercera. Unas coplas | al } \\
\text { tono de, Madre mia } \mid \text { dexedesme. | I La quarta. Unas coplas | a nuestra } \\
\text { señora, que di=| zen, En bon punt, y en | bon hora. | } Y \text { vn romance } \\
\text { dela Resur } \mid \text { rection. | g Otro romance de otro | autor. }\end{array}$ \\
\hline $22-23^{v}[4]$ & $\begin{array}{l}\text { Coplas de: si me vieras | Juan, a lo spiritual; nueuamen } \mid \text { te compuestas. } \\
\text { Año. | M.D.L.viij. | Jmpresso en Cuenca. }\end{array}$ \\
\hline $28-31^{v}[3]$ & $\begin{array}{l}\text { AQVI COMIENCAN | tres Romances y otros muchos villan } \mid \\
\text { cicos, sacados de la sagrada escriptura. El primero del } \mid \text { cielo salio vn } \\
\text { archangel. El segundo de caluario salio el } \mid \text { demonio. El tercero que } \\
\text { en los mas altos confines de aquel | precioso madero. Y vna obra a la } \\
\text { sanctissima hostia. Y otra } \mid \text { al caliz. Agora nueuamente compuestos, y } \\
\text { endereçados | al muy reuerendo señor Diego de Louera, ca= | nonigo } \\
\text { de salamanca mi señor. | Ańo .de. M.d.lvij. }\end{array}$ \\
\hline
\end{tabular}




\begin{tabular}{|c|c|}
\hline $48-51^{v}[5]$ & $\begin{array}{l}\text { S Siguese vn romance de la } \mid \text { passion de nuestro señor Jesu Chri= } \\
\mid \text { sto al tono de cauallero de ar } \mid \text { mas blancas. Agora nue } \mid \text { uamente } \\
\text { impresso. | Jmpresso en Cuenca. }\end{array}$ \\
\hline $52-55^{v}[7]$ & $\begin{array}{l}\text { g Coplas que hizo don Jorge Manri | que ala muerte del maestro de } \\
\text { Sanctiago | don Rodrigo Manrique | su padre. }\end{array}$ \\
\hline $\begin{array}{l}114-117^{\mathrm{v}} \\
\quad[1]\end{array}$ & $\begin{array}{l}\text { g Verdadera relacion } \mid \text { de como vn rustico labrador } \mid \text { con su buena } \\
\text { astucia, y con } \mid \text { sejo de su muger enga= } \mid \text { ńo a vnos mercade= } \mid \text { res por } \\
\text { muy gen } \mid \text { til estilo. } \mid \text { Impresso en Cuenca. } \mid \text { M.D.LVII. }\end{array}$ \\
\hline
\end{tabular}

A partir de las portadas que reproducimos al final de este artículo, podemos constatar que [4] y [5] comparten una misma orla xilográfica de cuatro piezas, con decoración de florones y cabezas humanas, cuyo diseño es exactamente el mismo que figura en el frontispicio de la Farsa llamada Rosiela (Cuenca, 1558). ${ }^{3}$ Este impreso y [5] coinciden en el hecho de mencionar el mismo año y la misma localidad sin aludir al impresor. De todos modos, la crítica ya ha atribuido la Farsa a Juan de Cánova, porque dos de las cuatro piezas fueron utilizadas en la Tragicomedia de Calisto y Melibea compuesta por el bachiler Fernando de Rojas (Cuenca, Juan de Cánova, 1561). ${ }^{4}$ El mismo diseño de florones y cabezas humanas, aunque no de cuatro piezas sino de dos, aparece por lo menos en dos ediciones salidas de la tipografía de Lorenzo de Soto, que trabajó en Martín Muñoz entre los ańos 1570 y $1576 .^{5}$ A pesar de las diferencias -casi imperceptibles-que pueden observarse entre las orlas impresas por ambos tipógrafos, nos inclinamos

3. En García Morales (1962: II, 265-286, núm. XXIV), hemos consultado un facsímil del único ejemplar conocido, custodiado en la Biblioteca Nacional de España [R/2251], cuya portada dice: «Farsa llamada Rosiela nue| uamente compuesta: en la qual se intro | duzen las personas siguientes. Palo $=\mid$ meo padre de Foriseo [sic]. Rosiela dama. | Justina criada. Floriseo galan. Ca | niuano padre de Benito bo | uo. Pinamarte criado de | Palomeo Mangre | ja y Pabros gil. | †».

4. Remitimos a las descripciones de Alfaro Torres (2002: 119-125, núms. 19 y 24). Este catálogo tipobibliográfico omite una importante edición que también utiliza dos de las cuatro piezas de la orla xilográfica que aparece en [4] y [5]. Se trata de La historia de Grisel y Mirabella con la disputa de Torrellas y Braçayda: la qual compuso Juan de Flores (Cuenca, Juan de Cánova, 1561), cuyo único ejemplar conocido forma parte de la Biblioteca Pública de Évora [Séc. XVI-2725].
Véase la reproducción de la portada en Livros (1966: 57).

5. Esta orla, que mide $163 \times 113 \mathrm{~mm}$, es reproducida a tamaño reducido por Reyes Gómez (1997: 42, figura 17), que dedica las pp. 37-44 al estudio de la imprenta de Lorenzo de Soto, donde advierte la conexión de este impresor con Juan de Cánova. La orla de la que hablamos es utilizada en la Relacion del espantable temblor y tempestad de rayos (Martín Muñoz, Lorenzo de Soto, 1571) [Biblioteca Nacional de España, R/31364]; y en la Escalera del cielo, fabricada por el glorioso doctor Sant Jeronymo (Martín Muñoz, Lorenzo de Soto, 1574) [Biblioteca de la Real Academia Española de la Lengua, R-94]. Véanse las descripciones de Reyes Gómez (1997: 136-137, núms. 11-12). Puede consultarse un facsímil del primero de los dos impresos en Pliegos-Madrid (19571961: I, 29-36, núm. V). 
por pensar en una procedencia común de sus materiales, pues el grabado que figura en la portada de [5] coincide con el de dos ediciones de Lorenzo de Soto. ${ }^{6}$ También son constatables a simple vista las semejanzas entre [6] y [7]. En ambos casos hay una pequeña orla donde alternan como elementos decorativos manículas y pimientos, que ocupa solo la parte superior del folio, alrededor del título que encabeza cada uno de los pliegos en cuestión. La orla de [6] tiene dos piezas xilográficas que van de izquierda a derecha, una al extremo superior y otra al extremo inferior, la segunda de las cuales aparece también, junto con la combinación de manículas y pimientos, en una obra de Alonso de Cervantes titulada Glosa famosissima sobre las coplas que hizo don Jorge Manrique (Cuenca, Juan de Cánova, 1552 [sic?]). ${ }^{7}$

El análisis de algunas de las xilografías nos ha permitido atribuir [4], [5], [6] y [7] a Juan de Cánova. A esta lista podemos añadir [1], cuyo anagrama ya hemos comentado. Estas ediciones también se asemejan en el hecho de utilizar unos mismos tipos de calderón y un elemento decorativo vegetal, definido por Infantes (2013) como una édera, que aparece en las portadas de [1], [2], [3] y [4]. Podemos concluir, pues, que estos siete pliegos salieron del taller conquense de Juan de Cánova.

6. Reyes Gómez (1997: 43, figura 18) reproduce este grabado, que representa la crucifixión con un santo personaje a cada lado de la cruz, que seguramente se identifican con la Virgen María y san Juan. Fue impreso en el Espejo de la vida humana repartido en siete jornadas, aplicadas alos sietes dias de la semana (Martín Muñoz, Lorenzo de Soto, 1570) [Biblioteca Nacional de España, R/31685]; y en la Escalera del cielo, fabricada por el glorioso doctor Sant Jeronymo (Martín Muñoz, Lorenzo de Soto, 1574) [Biblioteca de la Real Academia Española de la Lengua, R/94]. Véase Reyes Gómez (1997: 136-137, núms. 10 y 12). 7. En relación a esta edición con la glosa de Alonso de Cervantes, véanse el facsímil de la portada en Pérez Gómez (1963, núm. 14) y la descripción bibliográfica de RodríguezMoñino (1997: 223-224, núm. 141). Sobre la datación de este pliego (conservado en un ejemplar en la Biblioteca Nacional de España [R/10265]; y en otro de la colección del marqués de Morbecq que conocemos por referencia indirecta), debe advertirse que en el verso del primer folio figura 1562 como ańo de la licencia, mientras que el colofón da la fecha de 1552. Alfaro Torres (2002: 126-127, núm. 26), entre otros autores, se inclina por datar el pliego en 1562, porque hasta ahora nunca se habían documentado ediciones conquenses de Juan de Cánova anteriores a 1558. Sea como sea, lo que gracias a $P$ está fuera de duda es que Juan de Cánova ya se había establecido en Cuenca en el año 1557. Algunas ediciones zaragozanas de la familia de impresores Millán utilizan las mismas piezas xilográficas de la orla de [6], tal como sucede en el Espejo y arte muy breue y prouechosa para ayudar a bien morir enel incierto dia y hora de la muerte. Compuesto por fray Jayme Montañes (Zaragoza, Juan Millán, 1565); y en la Obra muy prouechosa: no solo para los Sacerdotes, mas tambien para los penitentes: y para todo fiel Christiano. $Y$ llamase este presente tractado Baculus Clericalis. Compuesto por el reuerendo maestre Bartolome Cucala, maestro en sacra Theologia (Zaragoza, Agustín Millán, 1567). De ambas ediciones describen y reproducen la portada, respectivamente, Sánchez (1991: II, 150-152, núm. 458) y Obrębski (1999, lámina 31). El mismo diseño lo volvemos a encontrar en un pliego suelto sin indicación de lugar ni impresor ni año, pero sin duda zaragozano, custodiado en la Biblioteca de Catalunya [Esp. $858^{\circ}$ ]: « Ego sum qui peccaui. | [Grabado] | I Aqui hallaras lector con que trances | las dulces ficiones que van a mesura | [...]» (Blecua 1976: 233-240, 
En los párrafos precedentes nos hemos fijado en la materialidad de estas sietes ediciones. Pasaremos ahora a su descripción bibliográfica, poniendo especial énfasis en su contenido. Indicamos en primer lugar la ciudad, el impresor y la fecha. En este contexto y también en otros, marcamos entre corchetes la información que no figura de manera explícita, como sucede por ejemplo en la foliación. En contadas ocasiones, advertimos el tamaño de algunas iniciales con un factor numérico en superíndice, como equivalencia al número de líneas o versos que ocuparía la letra en cuestión. Además, se indica el inicio de cada poesía con una flecha $(\rightarrow)$ que, evidentemente, no aparece en los originales. De cada pliego se transcribe el frontispicio y el éxplicit, y de cada composición la rúbrica inicial y el íncipit. Sigue una breve referencia a la presencia o ausencia de foliación y signaturas de cuaderno, para pasar después al estudio bibliográfico de las obras, cada una de las cuales es identificada con una letra según el orden alfabético. Indicamos el nombre del autor siempre que sea posible, aunque lo hacemos entre corchetes cuando solo es aludido en otros testimonios diferentes a los de $P$. Como — salvo [1] — los otros seis impresos incluyen poesías, hemos centrado nuestro estudio en esta faceta. Añadimos ahora un listado por orden alfabético con los poemas impresos en [2], [3], [4], [5], [6] y [7]:

núm. XXX). 
Primeros versos de las obras Contenidas en los Pliegos ConQUenses

Adórote, Hostia bendita, | bajo de cuya figura (3g)

Adórote, sangre santa | en ese cáliz metida (3h)

Arrojé mi corazón | a una casada (3n)

Creo al tu poder divino | ser asaz posible cosa (3d)

Cristo, Dios y hombre perfecto, | con sobrada caridad (6a)

Del Calvario salió el demonio; | del Calvario ya salia (3b)

Del cielo salió un arcángel, | de entre la gran monarquia (3a)

Dígasme tú, el caballero | Lázaro resucitado (5a)

Durmiendo iba el Señor | en una nave en la mar (6f)

En Jerusalén, | en monte sagrado (4a)

En las partes de Sidón, | que es en Tiro de Judea (6b)

En los más altos confines | de aquel precioso madero (3e)

Gloria in excelsis Deo. |-Di por quién. $\rightarrow$ Ya nació | el que principio nos dio $(4 \mathrm{~d})$

Madre mía, dejédesme; | que me llama, mas ;ay! que me llama (6c)

No me sigáis, Cancerbero, | pues que Dios (4c). Fragmento de: Verbum caro factum

est. | ¿ ¿Cómo lo sabes, nos di?

No sé si oís | llorar nuestro Dios (3k)

Oh glorias al Padre | y al Hijo también (31)

Oh santo sol radiante | de tan ardiente claror (2a). Fragmento de: Yo, el cimiento de tristura | y dolor contra alegría

Preguntaba la doncella | a san Gabriel (3j)

Puix lo Fill de Déu és nat, | tota tristor vaja fora (6d)

Recuerde el alma dormida, | avive el seso y despierte (7a)

Señor Dios que me hiciste | de nada varón entero (3c)

Si me parto, madre mía, |voyme a Dios (3f)

Si viniese y me llevase, | por vida mía que me salvase (4b). Fragmento de: Verbum caro

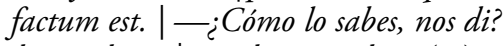

Venid, pecadores, | y ved vuestro bien (3i)

Venid, venid, oh cristianos, | venid todos muy de grado (6e)

Verbum caro factum est. | ¿Cómo lo sabes, nos di? $\longrightarrow$ Si viniese y me llevase | por vida mia que me salvase (4b) y No me sigáis, Cancerbero, | pues que Dios (4c)

Vi serrana de Belmar. | San Julián de buena estrena! (3m)

Ya nació | el que principio nos dio (4d). Fragmento de: Gloria in excelsis Deo. $\mid-D i$ por quién

$Y o$, el cimiento de tristura $\mid y$ dolor contra alegría $\longrightarrow$ Oh santo sol radiante $\mid$ de tan ardiente claror $(2 \mathrm{a})$

Para el estudio bibliográfico de cada una de estas obras, remitimos a otros pliegos quinientistas que también las transmiten. Para este propósito, ha sido de gran utilidad la consulta del Nuevo diccionario de Antonio Rodríguez-Moñino (1997), según la edición corregida y actualizada por Arthur L.-F. Askins y Víctor Infantes. Al mismo Rodríguez-Moñino (1973) debemos otro manual de referencia que completa el panorama de lo que fue la transmisión impresa de estas 
obras en cancioneros y romanceros impresos durante los ańos 1501-1600. Pocos testimonios pueden añadirse a los reseñados en estas bibliografías, aunque no es menos cierto que los datos recopilados a través de otros estudios que mencionaremos en el momento oportuno nos han permitido registrar copias manuscritas de poemas cuya transmisión impresa solo conocemos a través de $P .{ }^{8}$ Asimismo, hemos intentado subrayar la relación de contrafacta, adaptaciones y glosas con el texto tomado como modelo o con otras obras que parten del mismo. A pesar de nuestro esfuerzo por localizar los testimonios de una determinada composición, hay un considerable número de poesías que solo conocemos a través de $P$. Estos casos los hemos indicado ańadiendo la palabra latina Unicum.

En relación a la descripción de los pliegos y de las obras reunidas en cada uno de ellos, al final de este artículo adjuntamos un listado con las obras impresas del siglo XVI, excluyendo, de todos modos, los pliegos poéticos, pues en estos casos nos ha parecido suficiente remitir al ítem fijado en el Nuevo diccionario de Rodríguez Mońino (1997). Los impresos quinientistas son aludidos en cursiva a través del nombre abreviado de la obra o el apellido del autor más el año de edición; por ejemplo, $1 S 50$ y Mo54. Sigue al final la bibliografía crítica, que mencionaremos a través del apellido del autor, tal como ya hemos hecho en las páginas precedentes. Las descripciones de los pliegos poéticos han sido realizadas en gran parte sobre facsímiles y, en menor medida, a través de Rodríguez-Moñino (1997). En el caso de los demás impresos del siglo XVI, que figuran en el primer listado bibliográfico, no hemos recurrido, salvo algunas contadas excepciones, a la consulta de los ejemplares sino a las descripciones de Rodríguez-Moñino (1973).

\section{[1]}

\section{Cuenca, [Juan de Cánova], 1557}

[1a, fol. 1] [Tabernáculo, en cuyo interior se lee el siguiente título:] I Verdadera relacion $\mid$ de como vn rustico labrador $\mid$ con su buena astucia, y con $\mid$ sejo de su muger enga $=\mid$ ńo a vnos mercade $=\mid$ res por muy gen $\mid$ til estilo. $\mid \mathbf{g}$ Impresso en Cuenca. | M.D.LVII. | [Debajo del mencionado tabernáculo:] $\rightarrow \mathrm{M}^{5}$ Oraua en vn aldea vn labrador $\mid$ pobre que con mucha miseria passaua su vi= $\mid$ da $[$ Expl., fol. $\left.4^{\mathrm{v}}\right]$ Fin.

4 folios no numerados, sin signaturas ni reclamos.

$[1 \mathrm{a}] \longrightarrow$ Ruiz/Infantes (2012) han estudiado y publicado esta obra, sin olvidar el testimonio de $P$ que ahora estamos describiendo, "pero esta desconocida impresión conquense aporta una variante muy significativa en el capítulo quinto, no recogida en ningún otro testimonio» (Infantes 2013: 51). Véase, además, el

8. Hemos extraído de Jauralde Pou (19982008) todas las noticias a testimonios copiados en manuscritos de la Biblioteca Nacional de España. Data de los siglos XVII-XVIII el ms. 3661, mientras que los mss. 3768, 3880 y 4057 son ochocentistas. Para el resto de las fuentes, iremos indicando en su momento la bibliografía utilizada. 
panorama general que el mismo Infantes (2006: 84-85) ofrece sobre las sucesivas ediciones de este cuento tradicional, desde la etapa postincunable hasta el siglo XVIII.

[Cuenca, Juan de Cánova], 1557

[2a, fol. 1] OBRA NVEVAMEN- | te hecha, en la qual se contiene vna | platica de entre la Muerte y la Vida | sacada y traduzida de nueuo vergel | de Olorosas flores, sembradas por la $\mid$ dolorosa Muerte, y cogidas por la | trabajosa Vida. 1557. | [Dos grabaditos] | Argumento de la Obra. | NVEVO VERGEL DE | suaue arboleda de Olorosas flores se $m$ | bradas por la triste Muerte: y cogidas por la trabajosa vi $\mid$ da. Para sustentacion de los cuerpos humanos, y gloria $\mid$ para el anima. Nueuamente trobado. En el qual se trata | cierta platica entre la Muerte y la Vida, es de muy pro $=\mid$ uechosos y consolatorios exemplos para los mundanos. $\mid$ [Fol. 1 ${ }^{\mathrm{va}}$ ] Dize la vida. $\mid \rightarrow \mathbf{S} \mathrm{O}$ sancto sol radiante $\mid$ de tan ardiente claror | [Expl., fol. $\left.4^{\mathrm{vb}}\right]$ tu la reserua de pena | hijo de dios consagrado.

4 folios no numerados, sin signaturas ni reclamos. A doble columna a partir del fol. $1^{\mathrm{v}}$.

[2a] [Diego Bernal] $\rightarrow$ Fragmento de Yo, el cimiento de tristura $\mid y$ dolor contra alegría, impreso íntegramente en otro pliego poético sevillano de 1534, descrito por Rodríguez Moñino (1997: 169-170, núms. 53-54) y reproducido en PliegosMadrid (1957-1961: VI, 185-204, núm. CLXXXIX) a través de un ejemplar de la Biblioteca Nacional de España [R/3973].

\section{[3]}

\section{[Cuenca, Juan de Cánova], 1557}

[Fol. 1] [Alrededor de un grabado sobre la Anunciación hay una orla realizada a partir de tres barras xilográficas y diversos ornamentos tipográficos, bajo la cual se lee:] AQVI COMIENCAN | tres Romances y otros muchos villan | cicos, sacados de la sagrada escriptura. El primero del | cielo salio vn archangel. El segundo de caluario salio el $\mid$ demonio. El tercero que en los mas altos confines de aquel $\mid$ precioso madero. Y vna obra a la sanctissima hostia. Y otra $\mid$ al caliz. Agora nueuamente compuestos, y endereçados $\mid$ al muy reuerendo señor Diego de Louera, $\mathrm{ca}=\mid$ nonigo de salamanca mi señor. $\mid$ Año .de. M.d.lvij. | [3a, fol. $\left.1^{\text {va-vb }}\right] \rightarrow \mathrm{D}^{4}$ El Cielo salio vn $\mid$ archangel $\mid$ de entrela gran mo $\mid$ narchia $\mid[3 \mathbf{b}$, fol. $\left.1^{\mathrm{vb}}-2^{\mathrm{ra}}\right]$ Romance que $\mid$ dize Del Caluario salio el $\mid$ demonio. $\mid \rightarrow$ Del Caluario salio el de $=\left(\right.$ monio $\mid$ del caluario ya salia $\mid\left[3 \mathbf{c}\right.$, fol. $\left.2^{\text {rarb }}\right]$ A la hostia. $\mid \rightarrow$ Señor Dios que me heziste $\mid$ de nada varon entero $\mid\left[3 \mathrm{~d}\right.$, fol. $\left.2^{\text {rb }}\right] \mathrm{Al} \mathrm{Caliz.} \mid \rightarrow$ Creo al tu poder diuino $\mid$ ser assaz possible cosa $\mid\left[3 \mathrm{e}\right.$, fol. $\left.2^{\text {rb-va }}\right]$ Romance de la $\mid$ sagrada passion. $\mid \rightarrow$ En los mas altos confines $\mid$ de aquel precioso madero $\mid$ [3f, fol. $2^{\text {va- }}$ vb] Villancicos por desecha. $\mid \rightarrow$ Si me parto madre mia $\mid$ voy me a dios $\mid$ [3g, fol. $\left.2^{\text {vb }} 3^{\text {ra }}\right]$ A la hostia. $\mid \rightarrow$ Adorote hostia bendita $\mid$ baxo de cuya figura $\mid$ [3h, fol. $\left.3^{\text {ra }}\right]$ Al Caliz. $\mid \rightarrow$ Adorote sangre sancta $\mid$ en esse caliz metida | [3i, fol. $3^{\text {rarb }}$ ] 
Sotica. $\mid \rightarrow \mathbf{g}$ Venid peccadores | y ved vuestro bien | [3j, fol. $3^{\text {va-vb }}$ Cancion. $\mid \rightarrow \mathbf{g}$

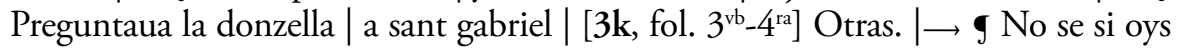
| llorar nuestro dios | [31, fol. $\left.4^{\text {rarb }}\right]$ Villancico al to | no de Para que se afeyta. $\mid \longrightarrow$ I O glorias al padre | y al hijo tambien | [3m, fol. $4^{\text {rb-vb }}$ Coplas. $\mid \rightarrow$ Viserreyna de belmar $\mid$ sant Julian de buena estrena $\mid\left[3 \mathbf{n}\right.$, fol. $\left.4^{\text {vb }}\right]$ Coplas. $\mid \rightarrow$ A Arroge mi coraçon | a vna casada | [Expl., fol. $\left.4^{\mathrm{vb}}\right]$ Deo gratias.

4 folios no numerados, con la signatura A ij (fol. 2) y sin reclamos. A doble columna a partir del fol. $1^{\mathrm{v}}$.

[3a] $\rightarrow$ Contrahace a lo divino, igual que [3b], el romance De Antequera partió el moro $\mid$ tres horas antes del día. $\rightarrow$ Cancioneros y romanceros: $1 S 50, S 50$ y $S 52$. $[3 \mathrm{~b}] \rightarrow$ Contrahace a lo divino, igual que [3a], el romance De Antequera partió el moro $\mid$ tres horas antes del día. $\rightarrow$ Juntamente con [3e] y [3m], este poema fue impreso en un pliego poético descrito por Rodríguez-Mońino (1997: 770, núm. 1012) y reproducido en Pliegos-Madrid (1957-1961: IV, 241-244, núm. CLXI) a través de un ejemplar de la Biblioteca Nacional de España [R/3661]. $\rightarrow$ Cancioneros y romanceros: $1 S 50, S 50$ y S52. $\rightarrow$ Zorita/DiFranco/Labrador (1991: 186-188, núm. 58) editan un testimonio copiado en el ms. 961 de la Real Biblioteca.

$[3 \mathrm{c}] \longrightarrow$ Unicum.

$[3 \mathrm{~d}] \rightarrow$ Unicum.

[3e] [Juan Tallante] $\rightarrow$ Impreso en el pliego poético indicado supra, en [3b]. $\rightarrow$ Cancioneros y romanceros: CG11, CG14, CG17, CG20, G[20], CG27, CG35, $C G 40,1 S 50, S 50, S 52, C G 57$ y CG73. $\rightarrow$ Este poema fue compilado, juntamente con [3f], [3g] y [3h], en el Cancionero de Pedro del Pozo, del año 1547, manuscrito que se cuenta entre los volúmenes del legado Rodríguez-Mońino-Brey de la Biblioteca de la Real Academia Española de la Lengua [RM 6952] (Rodríguez Moñino 1949-1950: 472; Madroñal 2004: 433). Con el inicio «En las más altas confines», también existe una copia del siglo XIx en el ms. 3880 de la Biblioteca Nacional de España.

[3f] [Juan Tallante] $\rightarrow$ Cancioneros y romanceros: CG11, CG14, CG17, CG20, G[20], CG27, CG35, CG40, CG57 y CG73. $\rightarrow$ Este poema fue compilado en dos volúmenes mencionados supra, en [3e]: por una parte, el Cancionero de Pedro del Pozo; por otra parte, el ms. 3880 de la Biblioteca Nacional de España. $[3 \mathrm{~g}] \rightarrow$ Copiado en el Cancionero de Pedro del Pozo, sobre el cual tratamos con más detalle en [3e].

$[3 \mathbf{h}] \rightarrow$ Copiado en el Cancionero de Pedro del Pozo, sobre el cual tratamos con más detalle en [3e].

$[3 i] \longrightarrow$ Unicum. En un manuscrito del siglo xvI, el ms. 5491 de la Biblioteca Nacional de España, se transmite un villancico cuyo estribillo comienza: «Se me bem quereis». Al cual sigue la primera copla, con el siguiente íncipit: «Vení, peccadores». Aunque se trata del mismo inicio del poema que ahora nos ocupa, podemos deducir sin dificultades que estamos ante dos obras diferentes. El texto que ahora nos ocupa también debe relacionarse con la siguiente copla inserta en 
el Códice de autos viejos: «Venid, pecadores, | a gustar del pan, | deste pan sagrado | en que a Dios nos dan» (Rouanet 1901: 125, núm. LXVII, vv. 107-110; cf. Becker 2005: 245).

$[3 \mathbf{j}] \longrightarrow$ Unicum.

$[3 \mathrm{k}] \rightarrow$ Unicum.

[31] $\rightarrow$ Unicum. Al tono de ¿Para qué se afeita la mujer? Frenk (2003: II, 1258, núm. 1746) aduce una buena diversidad de testimonios con este refrán.

$[3 \mathrm{~m}] \rightarrow$ Impreso en el pliego poético indicado supra, en [3b].

$[3 \mathbf{n}] \rightarrow$ Unicum.

[4]

Cuenca, [Juan de Cánova], 1558

[Fol. 1] [Orla de cuatro piezas alrededor de un grabado que representa a Cristo crucificado, con la Virgen Maria a un lado y san Juan al otro. Bajo esta imagen y todavía circunscrito por la orla, se lee el siguiente título:] Coplas de: si me vieras | Juan, a lo spiritual; nueuamen $\mid$ te compuestas. Año. | M.D.L.viij. | Jmpresso en Cuenca. | [4a, fol. $\left.1^{\text {va }} 2^{\text {rb }}\right] \longrightarrow \mathrm{E}^{2} \mathrm{n}$ Hierusalem $\mid$ en monte sagrado $\mid\left[4 \mathbf{b}\right.$, fol. $\left.2^{\text {rb }}\right]$ g Cancion de natura $\mid$ leza humana. $\mid \rightarrow$ Si viniesse y me lleuasse $\mid$ por vida mia que me saluasse. | [4c, fol. $\left.2^{\mathrm{rb}-\mathrm{va}}\right]$ otra cancion de na $\mid$ turaleza. $\mid \rightarrow$ No me sigays Cancerbero | pues que dios | [4d, fol. $\left.2^{\text {vavb }}\right]$ g Otra Cancion que | cantan vnos y responden $\mid$ otros. $\mid \rightarrow$ Ya nascio | el que principio nos dio. | [Expl., fol. $2^{\mathrm{vb}}$ I Deo gratias.

2 folios no numerados, sin signaturas ni reclamos. A doble columna a partir del fol. $1^{v}$. Se conservan tres testimonios en $P$, los dos primeros solamente con el primer folio, y el tercero completo.

[4a] $\rightarrow$ La misma canción es utilizada como refrán en $S A 61$ : «En sant Julián, | de somo el collado, | ¡si me vieras, Juan, | jugar al cayado! | A poderme ver | vieras la destreza» (Timoneda 1993: 76). Y también en una letrilla atribuida y desatribuida a Góngora (1980: 217-219), que, después de reiterar esta misma cuarteta, continúa: «Subieron ayer $\mid$ del cerro a la ermita». Diversas adaptaciones de esta canción son anotadas en Labrador/DiFranco/Montero (2006: 529) y Timoneda (1993: xii). $\rightarrow$ Un pliego poético de la Colección del marqués de Morbecq transmite un testimonio del poema que ahora nos ocupa (RodríguezMoñino 1962: 118 y 303-310, núm. XXVII; 1997: 584-585, núm. 708). Otro pliego de la Biblioteca Nacional de España [R/37909], que no hemos consultado, continene una glosa de Gabriel de Sarabia (Rodríguez-Moñino 1997: 476, núm. 541.5).

[4b] [Jorge de Montemayor] $\rightarrow$ Como [4c], este fragmento forma parte del segun-

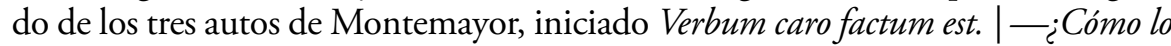
sabes, nos di? Estos autos fueron impresos en Mo54 (Whyte 1928: 970). Contrahace a lo divino los siguientes versos consignados en el Vocabulario de Correas: «Si viesse e me levasse, | por mińa vida, que no gridase! | Meu amigo atán garrido, | si viesse o domingo, | por mińa vida, que no gridasse!» (Frenk 2003: I, 408). 
[4c] [Jorge de Montemayor] $\rightarrow$ Como [4b], este fragmento forma parte del segundo de los tres autos de Montemayor, iniciado Verbum caro factum est. I - ¿Cómo lo sabes, nos di? Estas composiciones fueron impresas en Mo54. En realidad, el fragmento en cuestión es un contrafactum vuelto a lo divino de No me sirváis, caballero, | ios con Dios, canción también imitada en Mi61: «No me sirváis, caballero: ¡ýos con Dios! ¿Qué quién haze malas coplas? Nescio: ¡vos!»; «No me sirváys, caballero. Hios con Dios, que pelliscada voy por vos»; «No me sirvays, cavallero, ýos con Dios, que purgada estoy por vos» (Milà 2001: 224, 523 y 670). Véanse Frenk (2003: I, 482-483, núm. 711), Pliegos-Madrid (19571961: I, 125-132, núm. XVII), Rodríguez-Moñino (1997: 501-502, núm. 579) y Whyte (1928: 972).

[4d] [Jorge de Montemayor] $\rightarrow$ Este fragmento forma parte del último de los tres autos de Montemayor, iniciado Gloria in excelsis Deo. |-Di por quién. Estas composiciones fueron compiladas en Mo54 (Whyte 1928: 970). $\rightarrow$ Este mismo fragmento fue impreso en un pliego poético del año 1552, cuyo único ejemplar conocido en la actualidad pertenece a la Bibliothèque Municipale de Besançon [249-224 (2)]. Remitimos a Rodríguez-Moñino (1997: 376-377, núm. 380.5), Montemayor (2006: 7-8 y 520) y Dupont (1973).

\section{[5]}

\section{Cuenca, [Juan de Cánova, circa 1558]}

[5a, fol. 1] [Orla de cuatro piezas alrededor de Cristo en el Calvario, con un santo personaje a cada lado de la cruz, seguramente identificados el uno con la Virgen Maria y el otro con san Juan. Debajo del grabado se lee:] I Siguese vn romance de la $\mid$ passion de nuestro señor Jesu Chri= | sto al tono de cauallero de ar | mas blancas. Agora nue | uamente impresso. | Jmpresso en Cuenca. | [Fol. $\left.1^{\mathrm{va}}-4^{\mathrm{vb}}\right] \longrightarrow \mathrm{D}^{2}$ Jgas me tu el caualle $=\left(\right.$ ro $\mid$ Lazaro resuscitado $\mid\left[\right.$ Expl., fol. $\left.4^{\mathrm{vb}}\right]$ Amem. | Deo gratias.

4 folios no numerados, con la signatura B ij (fol. 2) y sin reclamos. A doble columna a partir del fol. $1^{\mathrm{v}}$.

$[5 \mathrm{a}] \rightarrow$ De este extenso romance devoto se conocía hasta ahora la noticia indirecta y parcial de la existencia de un pliego suelto impreso en Sevilla por Bartolomé Pérez en 1534, tal como puede observarse en la descripción que Arthur L.-F. Askins y Víctor Infantes añaden en el Nuevo diccionario de Rodríguez-Moñino (1997: 812, núm. 1083.5). Dicho ejemplar, entonces en paradero desconocido, podría ser el que actualmente pertenece a la Biblioteca Nacional de España [R/41101]. Estudiamos y editamos este pliego en Rovira i Cerdà (2015b).

[6]

Cuenca, [Juan de Cánova, circa 1558]

[Fol. 1] [Ocupa la mitad superior del folio una orla formada en los extremos horizontales por dos barras y en los verticales por diversos ornamentos tipográficos que representan maniculas y pimientos. En el interior se lee:] Siguen se quatro 
obras compuestas | por Nofre Almodeuar. | [Fol. $1^{\text {ra }}$ I La primera es vn chiste sa | cado ala letra sobre el euan $\mid$ gelio dela Samaritana. | I La segunda. El chiste de | la Chananea. | I La tercera. Unas coplas | al tono de, Madre mia | dexedesme. | [Fol. $1^{\text {rb }}$ ] La quarta. Unas coplas | a nuestra señora, que di= | zen, En bon punt, y en | bon hora. | 9 vn romance dela Resur | rection. | I Otro romance de otro $\mid$ autor. $\mid\left[6 \mathbf{6}\right.$, fol. $\left.1^{\text {ra }}-2^{\mathrm{vb}}\right] \rightarrow$ Christo dios y hombre perfe $=\left(\right.$ cto $\mid$ con sobrada charidad $\mid\left[\mathbf{6 b}\right.$, fol. $\left.2^{\text {vb }}-3^{\text {ra }}\right]$ Comiença el chiste $\mid$ dela Cananea. $\mid \rightarrow$ En las partes de Sydon | ques en Tyro de Judea. | [6c, fol. $3^{\text {rb-va }}$ ] Coplas hechas al to- $\mid$ no de Cauallero dexedes $\mid$ me: por buen $\mid$ estilo. $\mid \rightarrow \mathbf{g}$ Madre mia dexedesme $\mid$ que me llama, mas ay que me lla = (ma $\mid\left[6 \mathrm{~d}\right.$, fol. $3^{\mathrm{va}}-$ $4^{\text {ra }}$ I Cobles dela mare $\mid$ de Deu al to de en bon $\mid$ punt y en bon hora. $\mid \rightarrow \mathbf{g}$ Puix lo fill de Deu es nat $\mid$ tota tristor vaja fora $\mid\left[6 \mathrm{e}\right.$, fol. $\left.4^{\text {rb-va }}\right]$ gomance de la glo $\mid$ riosa resurrecion de nue $=\mid$ stro señor Jesu Christo. $\mid \rightarrow$ Venid venid o christianos | venid todos muy de grado | [6f, fol. $\left.4^{\mathrm{va}-\mathrm{vb}}\right]$ Romance del comen- | dador Auila. $\left.\right|^{4 \mathrm{vb}} \rightarrow$ Dormiendo yua el señor $\mid$ en vna naue en la mar $[$ Expl., fol. $4^{\mathrm{vb}}$ ] Fin. [Fol. $4^{\mathrm{v}}$ ] Jmpresso en Cuenca.

4 folios no numerados, sin signaturas ni reclamos. A doble columna, excepto las rúbricas en el fol. 1 y el colofón en el fol. $4^{\mathrm{v}}$.

[6a] Onofre Almudéver $\rightarrow$ Unicum.

[6b] Onofre Almudéver $\rightarrow$ Cancioneros y romanceros: S50, S52 y DC54. Debemos la localización de este último testimonio a la gentileza del Dr. Félix Santolaria Sierra, que nos ha cedido una reproducción del único ejemplar conocido, pertenenciente a la Biblioteca Nacional de Portugal.

[6c] Onofre Almudéver $\rightarrow$ Unicum. Cantado al tono de Caballero, dexédesme, canción que no hemos localizado.

[6d] Onofre Almudéver $\rightarrow$ Unicum. Cantado al tono de En bon punt $i$ en bona hora, melodía que también aprovechó Timoneda en otra poesía catalana impresa en un pliego poético de la Biblioteca de Catalunya [Esp. $988^{\circ}$ ]. Remitimos a la descripción de Rodríguez-Moñino (1997: 490, núm. 561), al facsímil de Blecua (1976: 193-196, núm. 24) y a la edición de Romeu i Figueras (1949: 173-174). En la Cataluña del siglo xvi también eran conocidos este estribillo y su melodía, tal como se deduce del refrán de una poesía catalana de Galceran Durall copiada en el ms. 1723 de la Biblioteca de Catalunya (MCEM 2012, Id 211; Duran 1998: 286). Con este refrán y al mismo tono se estamparon en Barcelona Vos subáis, Virgen Señora y Que no es no, que ya no es nada. La primera pieza se encuentra en un pliego poético del Arxiu Històric de la Ciutat de Barcelona [B/1589-8 (op.) 1]. Ha sido descrito por Rodríguez Moñino (1997: 623-624, núm. 768.5) y existe un facsímil en Amades/Colomines (1946: 12-13, núm. V). La segunda pieza fue impresa en C91. En Rovira/Mahiques (2015) nos ocuparemos de la presencia del refrán En bon punt i en hora bona a la largo de la tradición poética catalana, desde el siglo xvi hasta la actualidad.

$[6 \mathrm{e}] \rightarrow$ Poema impreso en un pliego poético que describe Rodríguez-Moñino (1997: 744, núm. 961) y reproduce Blecua (1976: 273-276, núm. XXXVI) en 
facsímil a partir de un ejemplar de la Biblioteca de Catalunya [Esp. $828^{\circ}$ ]. $\longrightarrow$ Cancioneros y romanceros: 3551 .

[6f] Comendador Ávila $\longrightarrow$ Tal como indica Rodríguez-Mońino (1997: 702-703, núm. 901), en la Bibliothèque Nationale de France [Rés P Y2 232] hay un pliego con la Historia del virtuoso cauallero don Tungano (Toledo, Ramón de Petras, 1526) que incluye también un testimonio de este romance. $\rightarrow$ Cancioneros y romanceros: CG14, CG17, CG20, CG27, CG35, CG40, 3S51, CG57 y CG73. $\rightarrow$ Biblioteca Nacional de España: ms. 3880.

\section{[7]}

\section{Cuenca, [Juan de Cánova, circa 1558]}

[7a, fol. 1] [Dentro de una pequeña orla que ocupa la parte superior, formada de maniculas y pimientos, se lee:] g Coplas que hizo don Jorge Manri | que ala muerte del maestro de Sanctiago | don Rodrigo Manrique | su padre. | [Debajo de la orla:] [Fol. $\left.1^{\mathrm{ra}}-4^{\mathrm{vb}}\right] \rightarrow \mathrm{R}^{2}$ ecuerde el alma dormida $\mid$ abiue el seso y despierte | [Expl., fol. $\left.4^{\mathrm{vb}}\right]$ I En su sepultura dize de | sta manera. | Aqui yaze muerto el hombre | que biuo queda su nombre. | 9 Fin. | [Fol. $\left.4^{\mathrm{v}}\right]$ Jmpresso en Cuenca. 4 folios no numerados, sin signaturas ni reclamos. A doble columna, excepto el título en el fol. 1 y el colofón en el fol. $4^{v}$.

[7a] Jorge Manrique $\longrightarrow$ Aparte de los testimonios glosados, transmiten estas coplas numerosos pliegos poéticos que describe Rodríguez-Mońino (1997: 339-343, núms. 326.5, 327, 328, 329, 330, 331, 332 y 333). La glosa más divulgada de las coplas manriqueñas es la de Alonso de Cervantes, como bien demuestra el extenso listado del diccionario de Rodríguez-Moñino (1997: 217-224, núms. 128, 129, $130,131,132,133,133.5,134,135,136,137,138,139,139.5,140,140.5,141$ y 141.5). En forma de pliego poético también nos han llegado dos glosas diferentes de Jorge de Montemayor y otra de Rodrigo de Valdepeñas (Rodríguez-Moñino 1997: 378 y 522, núms. 382, 383 y 619.8). De los pliegos con la glosa de Alonso de Cervantes se ha ocupado Askins (1989: 68-74), que parte del exhaustivo inventario de glosas a las coplas que ofrece Pérez Gómez (1963). Este último estudio no solo reseña las glosas editadas en forma de pliegos poéticos sino también en otros impresos de diferente formato e incluso en manuscritos. Adviértase, en todo caso, que uno de los pliegos de la glosa de Alonso de Cervantes, el núm. 141 del Nuevo diccionario, fue impreso en Cuenca por Juan de Cánova. $\rightarrow$ Cancioneros y romanceros: $C G 35$ y CG40. $\rightarrow$ Biblioteca Nacional de España: mss. 3661, 3768 y 4057. $\rightarrow$ Clasificar todas las ediciones de las coplas de Manrique aparecidas a lo largo del siglo XVI es una tarea que sobrepasa el espacio y la envergadura de las notas bibliográficas que ofrecemos en el presente estudio, aunque la bibliografía que citamos se ocupa de ello. Además de Pérez Gómez (1963), véanse Labrador/Zorita/DiFranco (1985) y Manrique (1991: 11-16). Vicente Beltrán realiza en este último trabajo un exhaustivo inventario de manuscritos, cancioneros impresos, pliegos sueltos y glosas. Aparte de las glosas, debe tenerse en cuenta la abundancia de contrafacta de este mismo texto, tal como sucede en el Cancionero general de la doctrina cristiana 
de Juan López de Úbeda (1962: I, 224), o en el Jardín espiritual \& Grandezas y excelencias de la virgen Nuestra Señora de Pedro de Padilla (2011: 286-292 y 440). Los editores de esta última obra añaden información sobre otras adaptaciones del modelo manriqueño a lo divino.

Hemos presentado y analizado desde el punto de vista bibliográfico siete pliegos atribuibles al taller conquense de Juan de Cánova, hacia los años 15571558. Mientras que [1], [2], [5] y [7] transmiten en cada caso una única obra, las otras tres ediciones incluyen varias poesías, en las que predomina la temática religiosa. Además, [3] y [6] reúnen un considerable número de piezas únicas, que no hemos registrado en ningún otro testimonio. Los poetas mencionados en [6] son Onofre Almudéver y el comendador Ávila, bien conocidos en el entorno valenciano del siglo xvi. El hecho de que Almudéver figure como autor de un poema en catalán (Puix lo fill de Déu és nat) nos hace sospechar que aunque [6] se estampase en Cuenca, fue ideado para ser comercializado en la ciudad del Turia. En efecto, no es difícil suponer que todos los pliegos de $P$, también aquellos salidos de Cuenca, se adquirieron en Valencia, ya que predominan los pliegos que asignamos a la tipografía valenciana de Joan Navarro (más del 70\%). Podemos concluir, pues, que los siete pliegos que hemos estudiado no solo completan el panorama de lo que fue la imprenta en Cuenca, sino que también constituyen un valioso documento sobre la transmisión literaria y el mundo de los libreros en la Valencia del siglo xvi.

\section{Obras impresas en el siglo XVI}

1S50. Primera parte dela Silua de varios Romances. En que estan recopilados la mayor parte delos romances Castellanos que hasta agora se han compuesto. Hay al fin algunas canciones: y coplas graciosas y sentidas, Zaragoza, Esteban G. de Nájera, 1550. [British Library: G. 10900, 1]

2CG52. Secvnda parte del Cancionero general: agora nueuamente copilado de lo mas gracioso y discreto de muchos afamados trobadores. Enel qual se contienen muchas Obras y Canciones Uillancicos Motes Chistes Preguntas Respuestas Galas: y Jnuenciones etc., Zaragoza, Esteban G. de Nájera, 1552. [Österreichische Nationalbibliothek: 72.5.146]

3S51. Tercera parte dela Silua de varios Romances. Lleua la misma orden que las otras., Zaragoza, Esteban G. de Nájera, 1551. [Hispanic Society of America]

C91. Cancionero de nvestra Señora: en el qual ay muy buenos Romances, Canciones y Villancicos. Aora nueuamente añadido, Barcelona, Viuda de Hubert Gotard, 1591. [Biblioteca de Catalunya: 6-VI-16]

CG11. Hernando del Castillo, Cancionero general de muchos y diuersos autores, Valencia, Cristóbal Koffman, 1511. [Ejemplares en Castillo 2004: I, 37-62] CG14. Hernando del Castillo, Cancionero general de muchos y diuersos auctores. Otra vez ympresso emendado y corregido por el mismo autor con adicion de muchas 
y muy escogidas obras: las quales quien mas presto querra ver vaya ala tabla y todas aquellas que ternan esta señal + son las nueuamente añadidas, Valencia, Jorge Costilla, 1514. [Bibliothèque Nationale de France: Rés.YG.9]

CG17. Hernando del Castillo, Cancionero general nueuamente añadido. Otra vez ympresso con adicion de muchas y muy escogidas obras: las quales quien mas presto querra ver vaya ala tabla: $y$ todas aquellas que ternan esta señal + son las nueuamente añadidas, Toledo, Juan de Villaquirán, 1517. [Ejemplares en Castillo 2004: I, 68-69]

CG20. Hernando del Castillo, Cancionero general nueuamente Añadido. Otra vez ympresso con adicion de muchas y muy escogidas obras: las quales quien mas presto querra ver: vaya ala tabla: $y$ todas aquellas que ternan esta señal. + . son las nueuamente añadidas, Toledo, Juan de Villaquirán, 1520. [Ejemplares en Castillo 2004: I, 68-69]

CG27. Hernando del Castillo, Cancionero general Agora nueuamente añadido. Otra vez ympresso con adicion de muchas y muy escogidas obras Las quales quien mas presto querra ver veya ala tabla: $y$ todas aquellas que ternan esta señal.X. son las nueuamente añadidas, Toledo, Ramon de Petras, 1527. [Ejemplares en Castillo 2004: I, 68-69)]

CG35. Hernando del Castillo, Cancionero general: enel qual se han añadido agora de nueuo enesta vltima impression muchas cosas buenas: ha sido con diligencia corregido y emendado, Sevilla, Juan Cromberger, 1535. [Ejemplares en Castillo 2004: I, 69-73]

CG40. Hernando del Castillo, Cancionero general: enel qual se han añadido agora de nueuo enesta vltima impression muchas cosas buenas: ha sido con diligencia corregido y emendado, Sevilla, Juan Cromberger, 1540. [Ejemplares en Castillo 2004: I, 69-73]

CG57. Hernando del Castillo, Cancionero general: que contiene mvchas obras de diuersos autores antiguos, con algunas cosas nueuas de modernos, de nueuo corregido y impresso, Anvers, Martin Nucio, 1557. [Ejemplares en Castillo 2004: I, 73-78]

CG73. Hernando del Castillo, Cancionero general: que contiene mvchas obras de Diuersos Autores antiguos, con algunas cosas nueuas de modernos, de nueuo corregido y impresso, Anvers, Philippo Nucio, 1573. [Ejemplares en Castillo 2004: I, 73-78]

DC54. Gregorio de Pesquera, Doctrina christiana, y Espejo de bien biuir: diuidi do en tres partes. La primera es vn dialogo ó coloquio entre dos niños con muchas cosas de la fe prouechosas, y la doctrina declarada y luego la llana. En la segunda se contienen muchas obras breues y de buena y sana doctrina. La tercera tiene muchas coplas y cantares deuotos para se holgar y cantar los niños, Valladolid, Sebastián Martínez, 1554. [Biblioteca Nacional de Portugal: No 829].

G[20]. Juan Fernández de Costantina, Cancionero llamado guirlanda esmaltada de galanes y eloquentes dezires de diuersos autores, [Sevilla, Juan Valera de Salamanca, circa 1520]. [Biblioteca Nacional de España: R/31621. Bayerische Staats- 
Bibliothek: Rar. 336.]

Mi61. Luís Milán, Libro intitulado el Cortesano, Valencia, Joan de Arcos, 1561. [Numerosos ejemplares conservados, por ejemplo en la Biblioteca Nacional de Espańa: R/1519, R/2427 y R/12933]

Mo54. Jorge de Montemayor, Las obras de George de Montemayor, repartidas en dos libros, Anvers, Juan Steelsio / Juan Lacio, 1554. [Biblioteca Nacional de España: U/744. Oviedo, Biblioteca de la Universidad. Bibliothèque de la Sorbonne].

S50. Silua de varios Romances: En que estan recopilados la mayor parte delos romances Castellanos, y agora nueuamente añadidos en esta segunda impresion que nunca an sido estampados. Hay al fin algunas canciones, villancicos y coplas, y tambien se an añadido en esta impresion algunas cosas sentidas, sacadas de diuersos auctores, Barcelona, Pedro Borin, 1550. [British Library: G.10901*]

S52. Silua. de varios Romances: En que estan recopilados la mayor parte delos romances Castellanos, y agora nueuamente añadidos enesta segunda impresion que nunca an sido estampados. Hay al fin algunas canciones villancicos y coplas, y tambien sean añadido enesta impresion algunas cosas sentidas, sacadas de diuersos auctores, Barcelona, Jaume Cortey, 1552. [Herzog August Bibliothek: A: 189 Poet]

S87. Silva de varios romances recopilados, y con diligencia escogidos los mejores Romances delos tres libros dela Silua. Y agora nueuamente añadidos cinco Romances dela armada dela Liga, y quatro dela sentencia de don Albaro de Luna, vno del cerco de Malta, otro dela mañana de sant Iuan, otro mira Nero de Tarpeya y otros muchos, Barcelona, Hubert Gotard, 1587. [Biblioteca de Catalunya: 6-VI-35]

SA61. Joan Timoneda, [Cancionero llamado Sarao de Amor], Valencia, Joan Navarro, 1561. [Biblioteca Nacional de España: R/3807. Ejemplar acéfalo, cuyo título está tomado del colofón] 


\section{Bibliografía}

Alfaro Torres, Paloma, La imprenta en Cuenca (1528-1679), Madrid, Arco Libros, 2002.

Amades, Joan / Colomines, Josep, Els goigs, vol. 1, Barcelona, Orbis, 1946.

Askins, Arthur L.-F., "Cinco pliegos poéticos no descritos del siglo XVI», Anuario de Letras, 24 (1986), 407-412.

—, Pliegos Poéticos Españoles de la British Library, Londres (Impresos antes de 1601), Madrid, Joyas Bibliográficas, 1989.

BeCKer, Danièle, «Intento de rescate de melodías en los autos del Códice de Autos Viejos", Criticón, 94-95 (2005), 209-327.

Blecua, José Manuel, Pliegos poéticos del s. XVI de la Biblioteca de Cataluña, Madrid, Joyas Bibliográficas, 1976.

Castillo, Hernando del, Cancionero general, 5 vol., ed. Joaquín González Cuenca, Madrid, Castalia, 2004.

Dupont, Jean, «Un pliego suelto de 1552 intitulé 'Cancionero de las obras de devoción de Jorge de Montemayor'», Bulletin Hispanique, 75 (1973), 40-72.

Duran, Eulàlia (dir.), Repertori de manuscrits catalans (1474-1620). Vol. 1. Barcelona: Arxiu històric i Biblioteca de Catalunya. Direcció: Eulàlia Duran. Compilació a cura de M. del Mar Batlle, Eulàlia Miralles, Maria Toldrà, Joan Tres, Barcelona, Institut d'Estudis Catalans, 1998.

Frenk, Margit, Nuevo Corpus de la Antigua Lírica Popular Hispánica (siglos XV a $X V I I), 2$ vol., México, Universidad Nacional Autónoma de México / Colegio de México / Fondo de Cultura Económica, 2003.

García Morales, Justo (prol.), Autos, comedias y farsas de la Biblioteca Nacional, 2 vol., Madrid, Joyas Bibliográficas, 1962-1964.

Góngora, Luis de, Letrillas, ed. Robert James, Madrid, Castalia, 1980.

Infantes, Víctor, Del libro áureo, Madrid, Calambur, 2006.

—, «Nuevas de poesía áurea. Cuarenta y dos pliegos poéticos desconocidos del siglo xvI, más dos en prosa», Hibris. Revista de Bibliofilia, 67-68 (enero - abril 2012), 39-45.

—, «Una cuarentena poética desconocida. Los pliegos sueltos del siglo XvI de la Biblioteca Comunale Augusta de Perugia», Criticón, 117 (2013), 29-63.

Jauralde Pou, Pablo (dir.), Catálogo de manuscritos de la Biblioteca Nacional con poesía en castellano de los siglos XVI y XVII, 7 vol., Madrid, Arco Libros, 1998-2008.

Labrador, José J. / DiFranco, Ralph A. / Montero, Juan, Cancionero sevillano de Toledo: manuscrito 506 (fondo Borbón-Lorenzana). Biblioteca de Castilla-La Mancha, Sevilla, Universidad de Sevilla, 2006.

Labrador, José J. / Zorita, C. Ángel / DiFranco, Ralph A., "Cuarenta y dos, no cuarenta coplas en la famosa elegía manriqueña», Boletín de la Biblioteca de Menéndez Pelayo, 61 (1985), 37-95.

Livros impressos no século XVI existentes na Biblioteca Pública e Arquivo Distrital de Évo- 
ra. II: Tipografia Espanhola, Évora, Publicações da Junta Distrital de Évora, 1966. López de ÚBEDA, Juan, Cancionero general de la doctrina cristiana, ed. Antonio Rodríguez-Moñino, Madrid, Sociedad de Bibliófilos Españoles, 1962.

Madroñal, Abraham, "Los manuscritos de la Biblioteca Rodríguez Moñino (hacia su catalogación y estudio)", La memoria de los libros. Estudios sobre la historia del escrito de la lectura en Europa y América. Tomo II. Bajo la dirección de Pedro M. Cátedra \& María Luisa López-Vidriero. Edición a cuidado de María Isabel de Páiz Hernández, Salamanca, Instituto de Historia del Libro y de la Lectura, 2004, 429-458.

Mahiques Climent, Joan / Rovira i Cerdè, Helena, «Un pliego poético atribuible a Juan de Cánova y un plagio de Bartomeu Auledes», Artifara. Revista de lenguas y literaturas ibéricas e hispanoamericanas, 13 (2013), 15/06/2013, $<$ http://www.ojs.unito.it/index.php/artifara/article/view/277>.

Manrique, Jorge, Coplas que hizo Jorge Manrique a la muerte de su padre, ed. Vicente Beltrán, Barcelona, PPU, 1991.

MCEM 2012 = Duran, Eulàlia (dir.) / Toldrà, Maria (coord.). MCEM (Base de dades de Manuscrits Catalans de l'Edat Moderna), Barcelona, Institut d'Estudis Catalans, 29/11/2012, <http://mcem.iec.cat>.

Milà, Lluís del, El cortesano, ed. Vicent Josep Escartí, Valencia, Biblioteca Valenciana / Ajuntament de València / Universitat de València, 2001.

Montemayor, Jorge de, Segundo cancionero espiritual. Amberes, 1558, ed. María Dolores Esteva de Llobet, Kassel, Reichenberger, 2006.

Овве̨вккі, Andrzęj, Volsciana. Catálogo de la biblioteca renacentista de Piotr DuninWolski, obispo de Ptock. / Volsciana. Katalog renesansowego ksiegozbioru Piotra Dunin-Wolskiego, biskupa Ptockiego, Cracovia, Ksiegarnia Akademicka / Instituto Cervantes de Varsovia, 1999.

Padilla, Pedro de, Jardin espiritual. Prólogo de Aurelio Valladares. Edición de José J. Labrador Herraiz, Ralph A. DiFranco, México, Frente de Afirmación Hispanista, 2011.

Pérez Gómez, Antonio, Glosas a las coplas de Jorge Manrique. Noticias bibliográficas, Cieza, La fonte que mana y corre, 1963.

Pliegos-Madrid = Pliegos Poéticos Góticos de la Biblioteca Nacional, 6 vol., Madrid, Joyas Bibliográficas, 1957-1961.

Reyes Gómez, Fermín de los, La imprenta en Segovia (1472-1900), vol. 1, Madrid, Arco Libros, 1997.

Rodríguez-Moñıno, Antonio, «El cancionero manuscrito de Pedro del Pozo (1547)», Boletín de la Real Academia Española, 29 (1949), 453-509; 30 (1950), 123-146 y 263-312.

—, Los pliegos poéticos de la colección del marqués de Morbecq (siglo XVI), Madrid, Estudios Bibliográficos, 1962.

-, Manual bibliográfico de cancioneros y romanceros impresos durante el siglo XVI, por Antonio Rodríguez-Moñino. Coordinado por Arthur L.F. Askins, 2 vol., Madrid, Castalia, 1973. 
-, Nuevo diccionario bibliográfico de pliegos sueltos poéticos (siglo XVI). Edición corregida y actualizada por Arthur L.-F. Askins y Victor Infantes, Madrid, Castalia, 1997.

Romeu i Figueras, Josep, Cançons nadalenques del segle XV, Barcelona, Barcino, 1949.

Rouanet, Léo, Coleccion de Autos, Farsas y Coloquios del siglo XVI. Publiée par Léo Rouanet. Tome III, Barcelona / Madrid, L'Avenç / M. Murillo, 1901.

Rovira I Cerdè, Helena, "Cinco romances en un pliego poético acéfalo», 2015a [Artículo enviado a una revista].

—, "Un romance al tono de Caballero de armas blancas más otras obras devotas: estudio y edición de un pliego poético reencontrado», 2015b [Artículo enviado a una revista].

Rovira i Cerdè, Helena / Mahiques Climent, Joan, «En bon punt $i$ en hora bona: presencia d'un refrany a la poesia catalana de les èpoques moderna i contemporània», 2015 [Artículo enviado a una revista].

Ruiz, Pedro / Infantes, Víctor, Dos obras de la primera literatura áurea (c. 1515). Cartas y coplas para requerir nuevos amores. Cómo un rústico labrador astucioso con consejo de su mujer engañó a unos mercaderes, Madrid, Turpin Ediciones, 2012.

SÁnchez, Juan M., Bibliografía aragonesa del siglo XVI. Edición facsímil, 2 vol., Madrid, Arco Libros, 1991.

Timoneda, Juan, Cancionero llamado Sarao de amor compuesto por Juan Timoneda, ed. Carlos Clavería, Barcelona, Delstre's, 1993.

VINDEL, Francisco, Escudos y marcas de impresores y libreros en España durante los siglos XV a XIX (1485-1850) con 818 facsimiles, Barcelona, Orbis, 1942.

Whyte, Florence, "Three autos of Jorge de Montemayor», Publications of the Modern Language Association of America, 43/3 (1928), 953-989.

Wilkinson, Alexander S., Iberian books. Books published in Spanish or Portuguese or on the Iberian Peninsula before 1601. / Libros ibéricos. Libros publicados en español o portugués o en la Peninsula Ibérica antes de 1601, Leiden, Brill, 2010.

Zorita, C. Ángel / DiFranco, Ralph A. / Labrador Herraiz, José J., Poesias del maestro León y de fr. Melchor de la Serna y otros (siglo XVI). Códice número 961 de la Biblioteca Real de Madrid, Cleveland, Cleveland State University, 1991. 


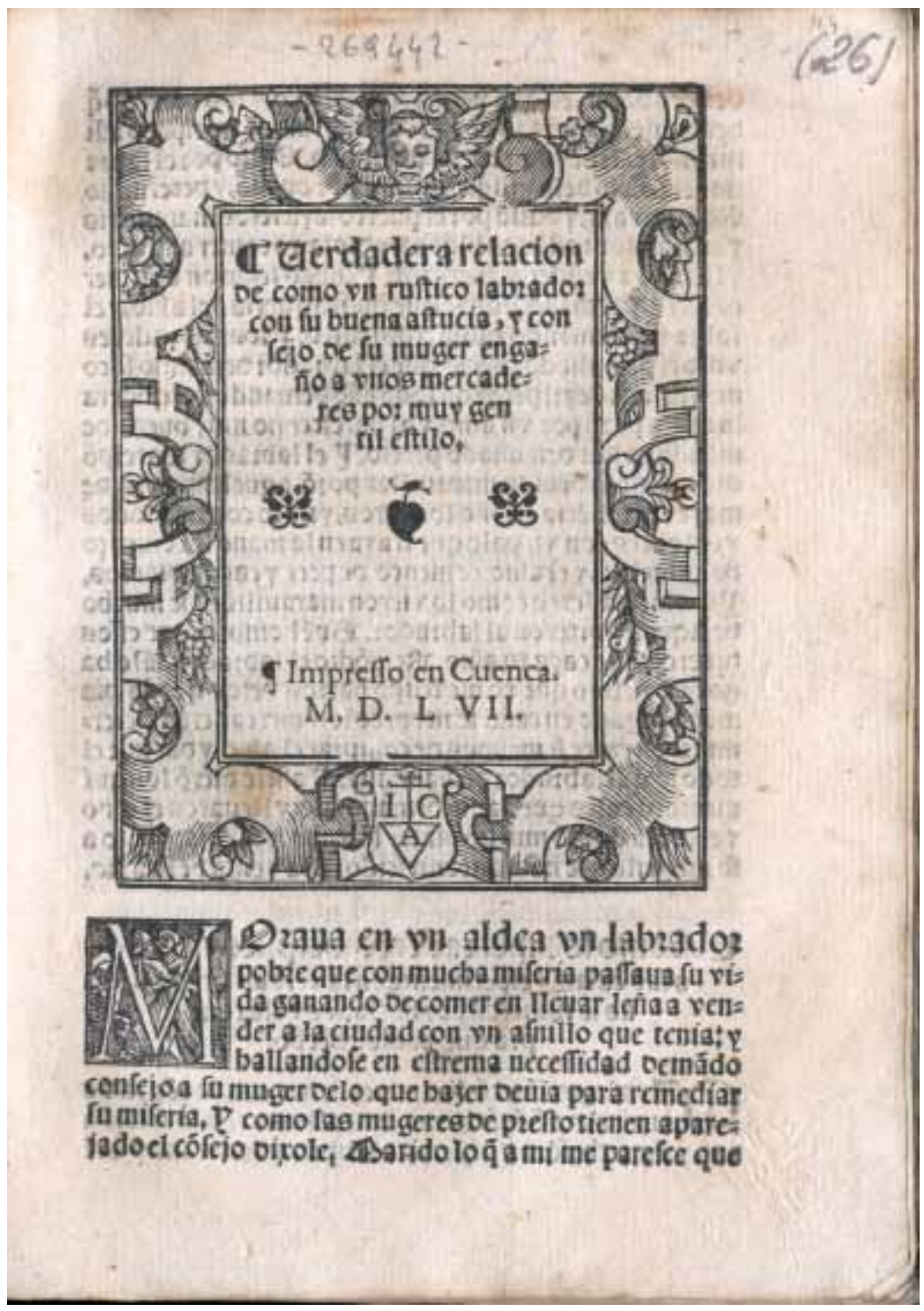

[1] Biblioteca Comunale Augusta de Perugia, [I L 1402], fol. 114 
OBRA NVEVAMENte hecha, en la qual fe contiene vna platica de entre la Muerte y la Vida facada y traduzida de nueuo vergel de Olorofas flores, fembradas por la dolorofa Muerte, y cogidas por la trabajofaVida. is 57.
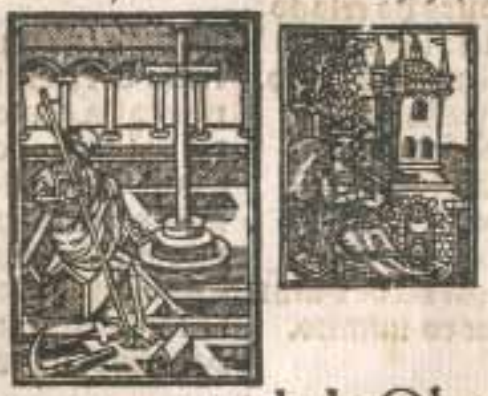

85 Argumento dela Obra.

EVEVO VERGEL DE fuaue arboleda de Olorofas flores fé

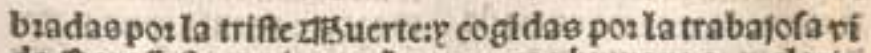
da. Para fuftentacion octee cuerpoe bumanos, $r$ glovia para el anima. ihueuamente trobado. En cl qualfe trata

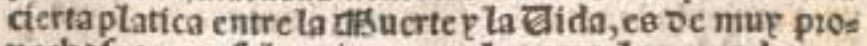
uecbofoer confolatovios eremplos para tos mundanos.

[2] Biblioteca Comunale Augusta de Perugia, [I L 1402], fol. 9 


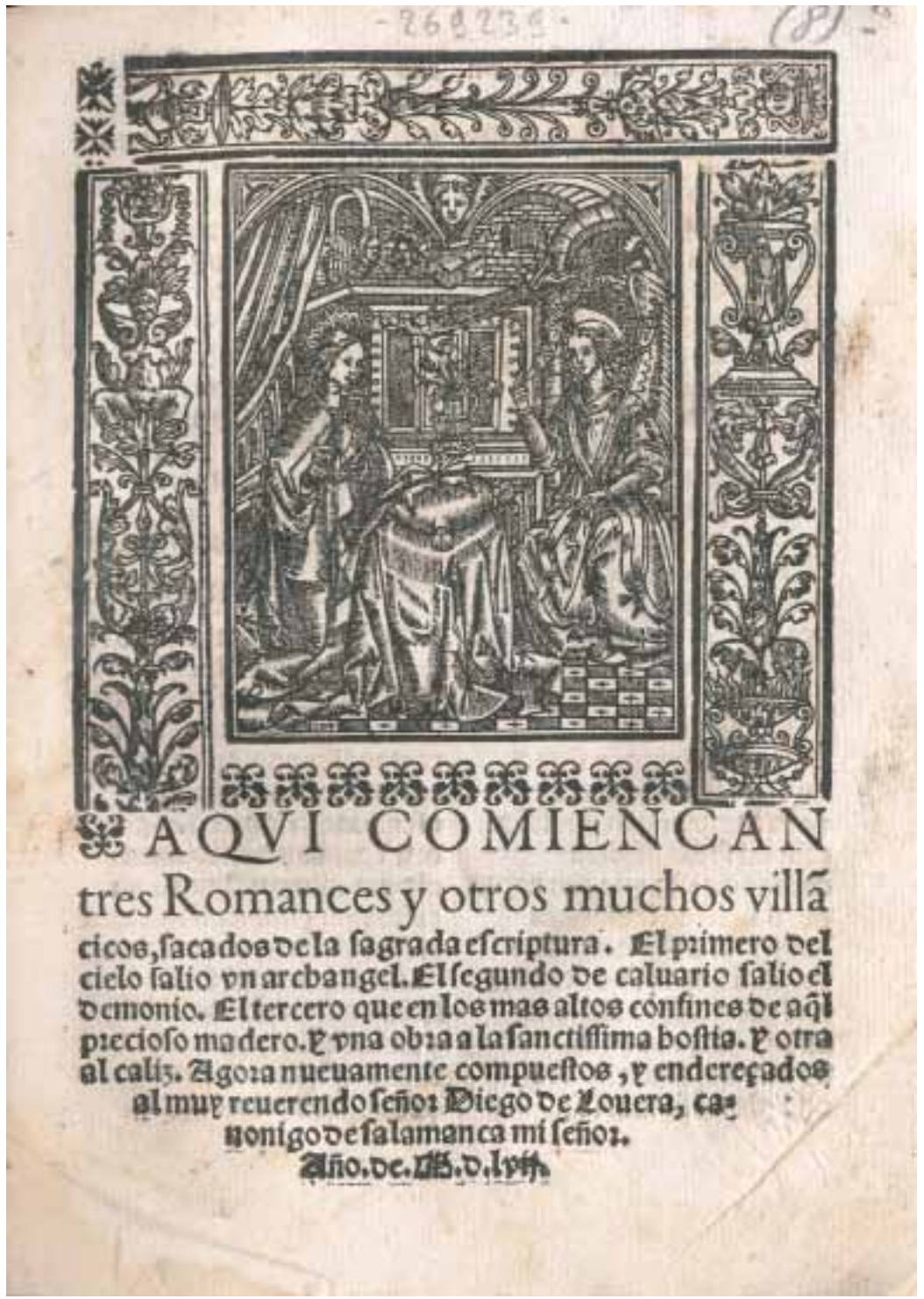

[3] Biblioteca Comunale Augusta de Perugia, [I L 1402], fol. 28 


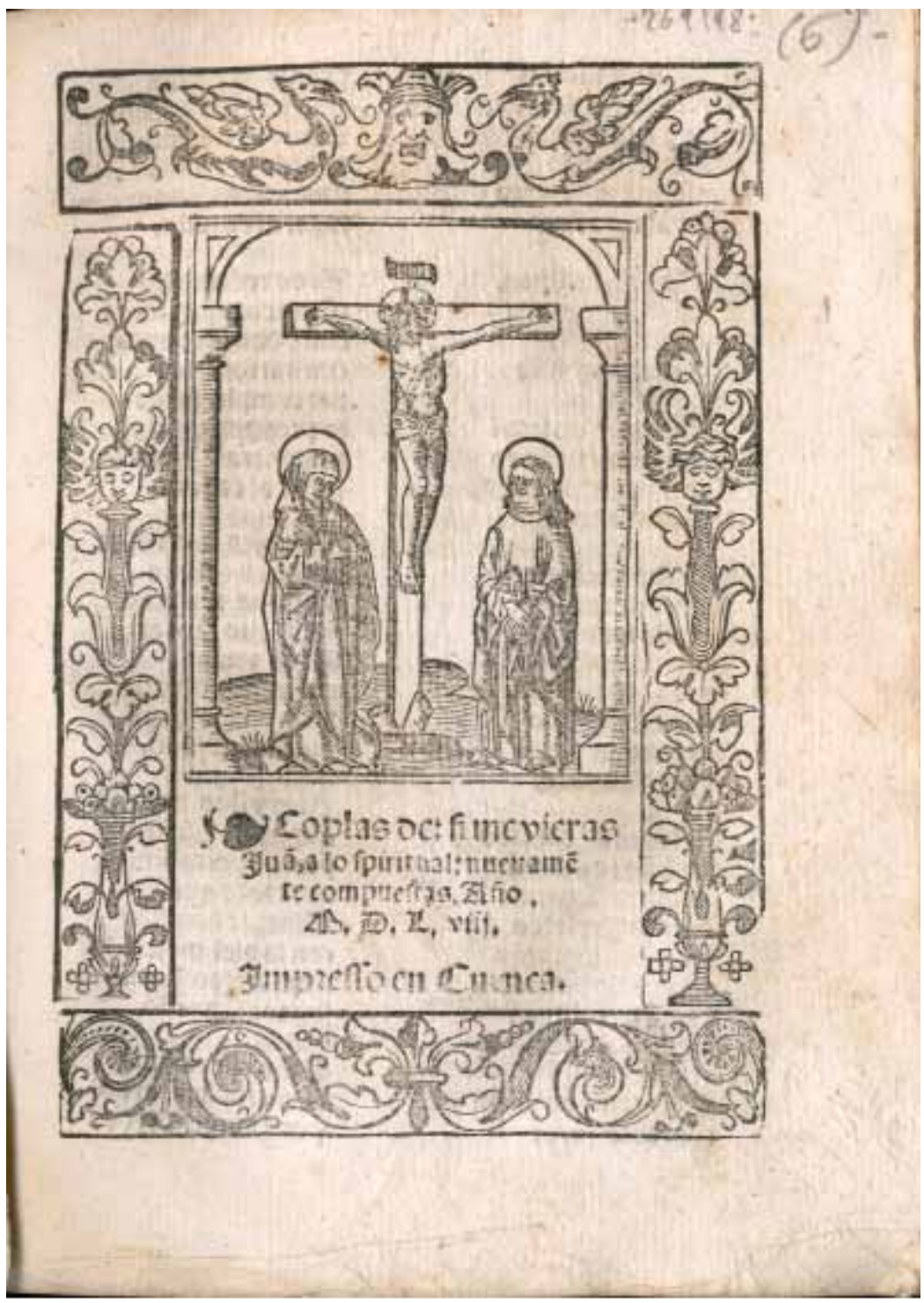

[4] Biblioteca Comunale Augusta de Perugia, [I L 1402], fol. 22 


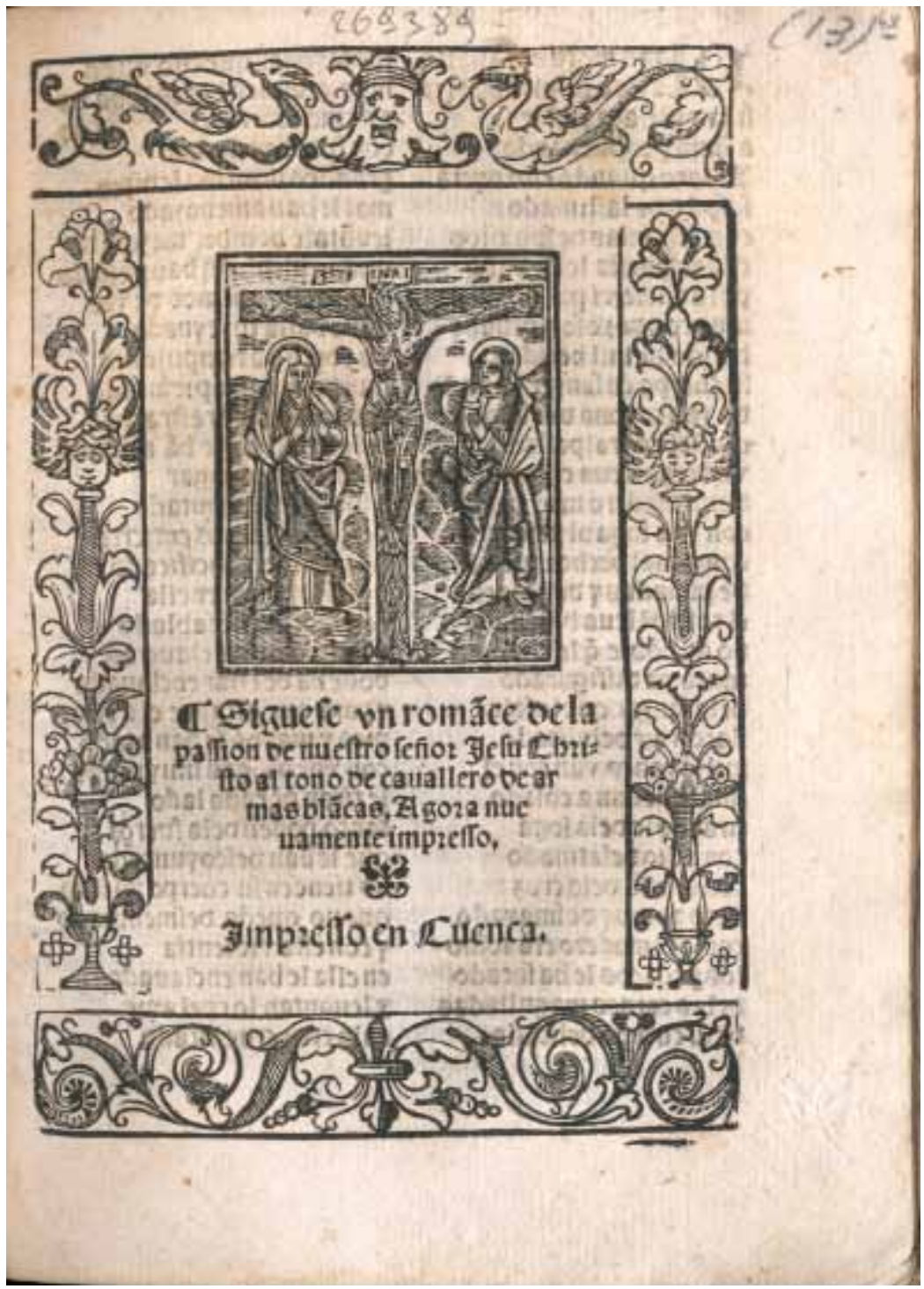

[5] Biblioteca Comunale Augusta de Perugia, [I L 1402], fol. 48 


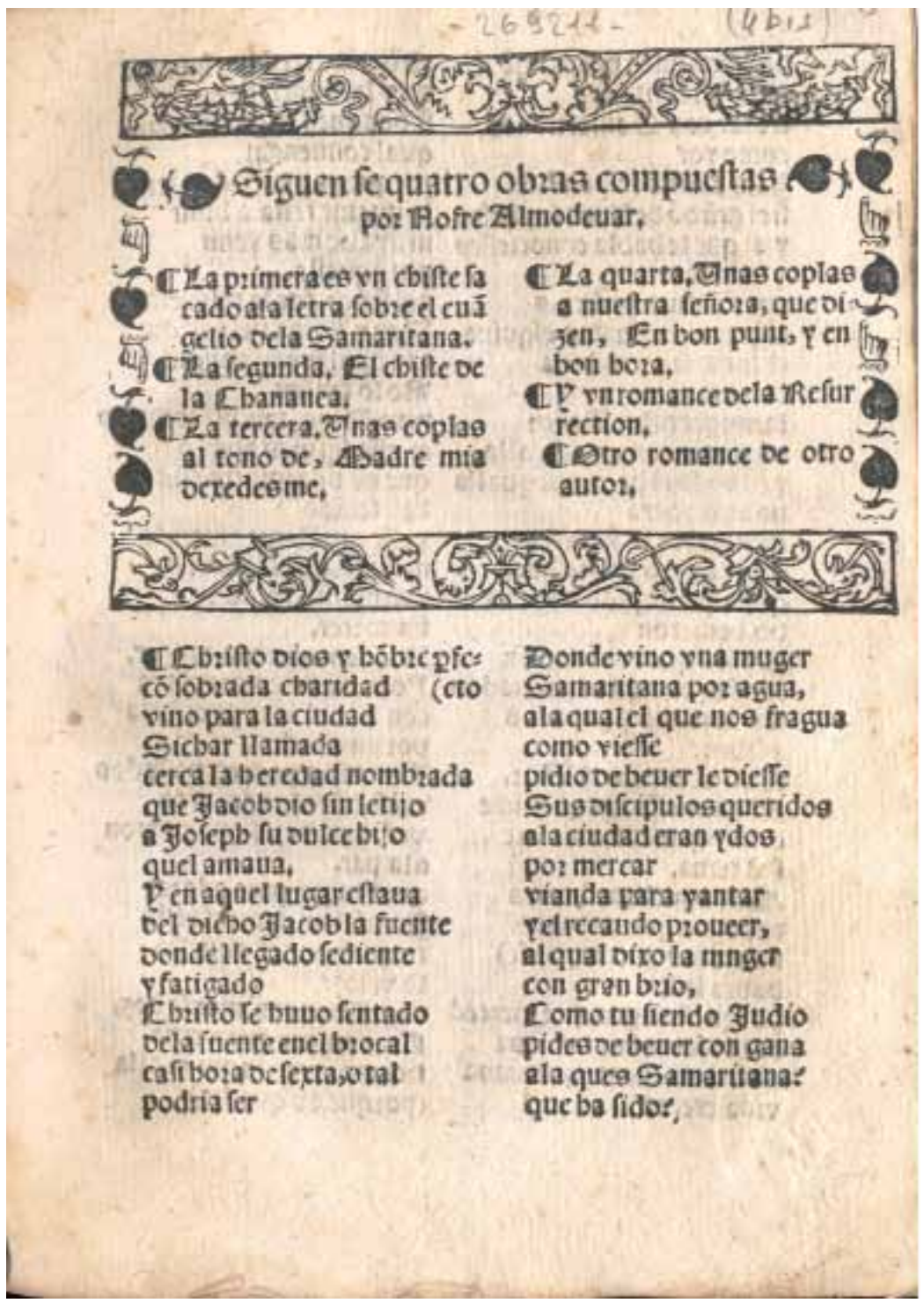

[6] Biblioteca Comunale Augusta de Perugia, [I L 1402], fol. 15 


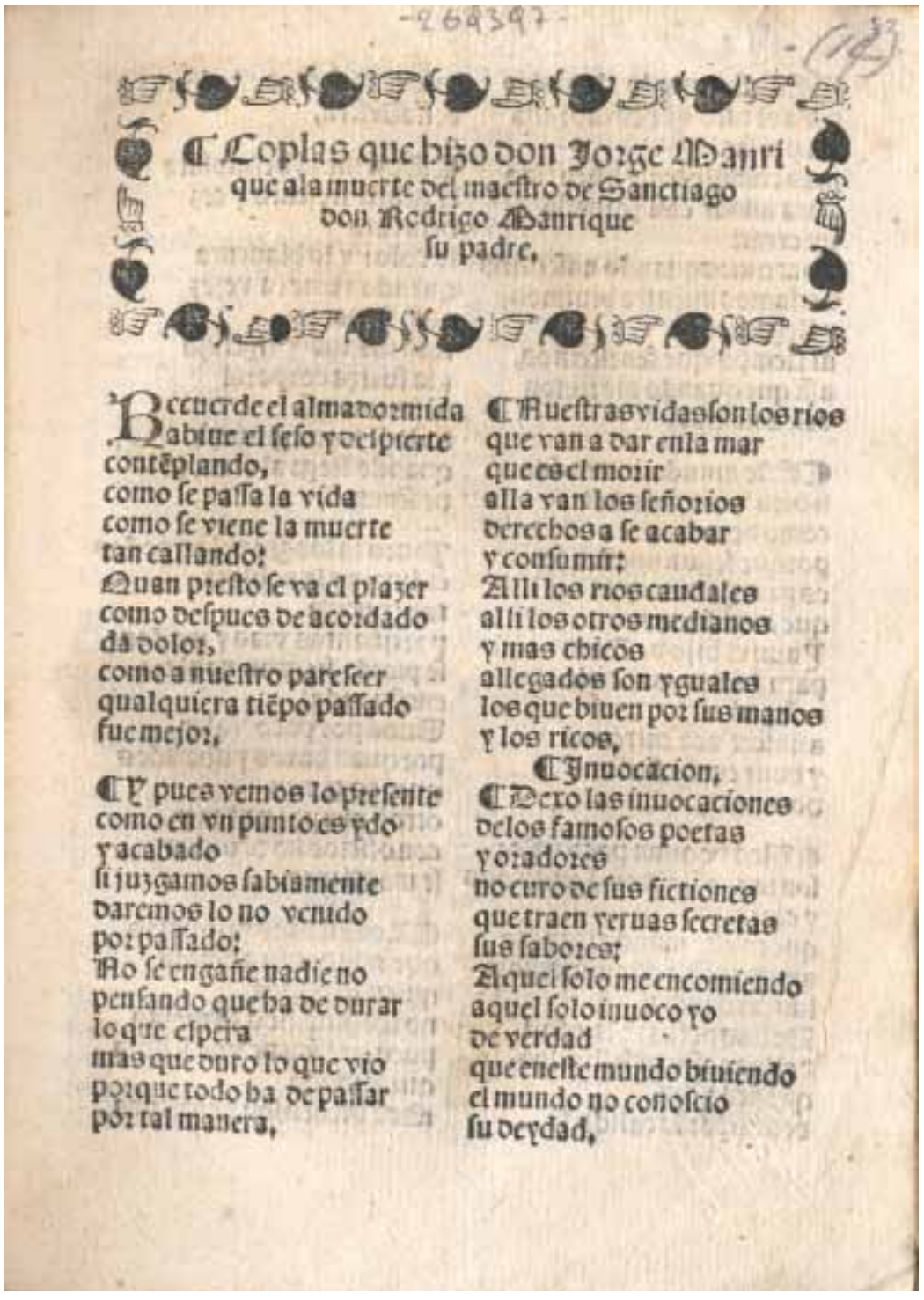

[7] Biblioteca Comunale Augusta de Perugia, [I L 1402], fol. 52 
